\title{
PSYCHIATRIC DISABILITY AND EMPLOYMENT
}

\section{A SURVEY OF 222 REGISTERED DISABLED PERSONS}

\author{
BY
}

\author{
M. MARKOWE, W. L. TONGE, AND L. E. D. BARBER \\ Medical Research Council Unit for Research in Occupational Adaptation
}

\section{(1) INTRODUCTION}

The social effects of neurosis no longer need to be stressed. This is especially true of occupation; the Disabled Persons (Employment) Act, 1944, is an outward sign of the common concern for the problems of the handicapped. It is generally assumed that psychiatric illness is particularly potent in damaging the capacity for work, and employers may turn men away for that reason. The previous work of this Unit has, however, largely failed to confirm this assumption (Markowe and Barber, 1952, 1953a, 1953b). These studies were concerned with men working in factories, of whom only a proportion had symptoms and all could be regarded, within broad limits, as adapted to their work.

The present investigation studied 222 men on the Disabled Persons Register with overt psychiatric disturbances. Subjects were selected because they had been heavily unemployed or else constantly employed over a certain period. The two groups were then compared in order to demonstrate that certain clinical features are associated with unsatisfactory employment records.

\section{(2) Previous Investigations}

Eisenberg and Lazarsfeld (1938) reviewed the psychological and social case-work studies on unemployed men and described the deterioration in morale which was observed in the unemployed Austrian village of Marienthal. They cited evidence that unemployed workers were more neurotic than employed men, and were more depressed about their future than neurotic patients (Morton, 1935; Israeli, 1935).

Lewis (1935) examined 52 men referred by the local Public Assistance Committee. He found a uniform clinical picture in which hysteria was predominant. Gross tremor was present in 23 patients and three showed a pseudo-dementia. Depression and irritability were common features, but not self-reproach, and there was much resentment and dissatisfaction, which however were described as a paranoiac reactive development of personality rather than as a paranoid delusional formation. In a follow-up one year later it was found that one-third of the men were no longer on out-relief and that many of the remainder were defective, epileptic, insane, elderly, or physically unfit.

Hewitt (1949) examined 50 unemployed disabled men, and found only seven free from psychiatric disability. He was impressed by their lack of interest in life and their pathological attitudes of resentment, aggression, and depression. In a follow-up one year later one-third had found employment, and Hewitt concluded that the attitude of mind of the disabled was the most important factor influencing employment.

In a follow-up of 103 patients discharged from the Belmont Industrial Neurosis Unit (Jones, 1952), those rated as having made a poor adjustment (including occupational adjustment) differed from the remainder in that more of them were single, had a long history of previous psychiatric illness, were more frequently unemployed before admission, and were more often diagnosed as schizophrenic or psychopathic. This confirms previous work (Stalker, 1945; Guttman and Thomas, 1946; Harris and Lane, 1949). Also reported (Jones, 1952) is a survey of psychiatrically disabled men with much unemployment, who had not been to Belmont. They were found to be disgruntled and embittered, in poorer health than the ex-patients, and with little hope for the future, either for work or for health. All these studies stress the importance of personality rather than psychiatric syndromes as a determinant of occupational adaptation.

\section{(3) MethoD}

The group of unemployed men studied in this investigation all had at least 6 months' unemployment during the years 1950-53, while the employed subjects had less than 
3 months' unemployment during the same period. All subjects had been registered at Employment Exchanges in South London as suffering from psychiatric disability. All the 95 unemployed subjects chosen were interviewed, but the 127 employed men who were seen formed only 22 per cent. of a much larger group, who were approached but did not attend for interview.

Each subject was interviewed for an hour by a psychiatrist and as full a history as possible was taken along customary lines. At the end of the interview a five-point rating was made of the subject's mental health on the basis of the history and psychiatric examination.* A physical examination was made where indicated, and an ischaemia pain endurance test was also carried out (Markowe and Barber, 1953b). After the psychiatrist's interview the occupational history was taken and the subject's present economic position assessed. Finally, all subjects were asked to do the Dominoes Test of general intelligence and to complete the Cornell Medical Questionnaire. In addition to information obtained at the interview, data were obtained also from the files of the Employment Exchange and the central offices of the Ministry of National Insurance and Pensions and the National Assistance Board, $\dagger$ and from the records of hospitals attended by the subjects.

\section{(4) Findings}

AGE.-The mean age of the 127 employed subjects was 42.43 years (S.D. $=11 \cdot 83$ ) and of the 95 unemployed $41 \cdot 65$ years $($ S.D. $=9 \cdot 66)$. These means do not differ significantly. The age distribution does not differ significantly from that given for adult males in the 1951 Census Report for the County of London (General Register Office, 1953).

Diagnosis.-Table I sets out the diagnostic categories of the subjects.

TABLE I

DIAGNOSIS

\begin{tabular}{|c|c|c|c|}
\hline Type of Disorder & Unemployed & Employed & Total \\
\hline 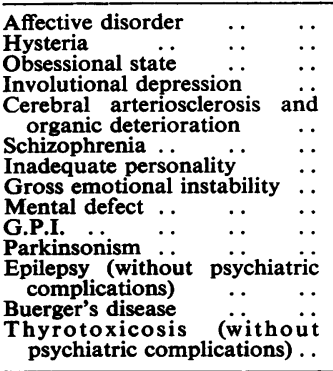 & $\begin{array}{r}25 \\
8 \\
4 \\
2 \\
4 \\
11 \\
19 \\
7 \\
14 \\
1 \\
- \\
- \\
-\end{array}$ & $\begin{array}{r}67 \\
11 \\
5 \\
8 \\
7 \\
7 \\
4 \\
8 \\
1 \\
10 \\
1 \\
1 \\
2 \\
1 \\
1\end{array}$ & $\begin{array}{r}92 \\
19 \\
99 \\
10 \\
11 \\
15 \\
27 \\
8 \\
24 \\
2 \\
1\end{array}$ \\
\hline Totals & 95 & 127 & 222 \\
\hline
\end{tabular}

* The ratings were: (1) "sympton free"; (2) "a few minor symptoms only"; (3) "some symptoms present, but no disability"; (4) "handicapped and distressed; may be receiving treatment from G.P., but does not require specialist psychiatric treatment"; (5)," "materially incapacitated; required specialist psychiatric treatment".

$t$ Permission was obtained from all subjects for these files to be consulted. (a) Affective Disorder, Hysterical and Obsessional States.-These diagnoses are equally represented amongst both employed and unemployed subjects, but many of the unemployed had either been ill for less than 3 years or else had a personality disturbance as a background to the illness (Table II). No type of personality disturbance was found more frequently amongst unemployed than employed subjects.

TABLE II

REVISED DIAGNOSTIC GROUPS AND EMPLOYMENT

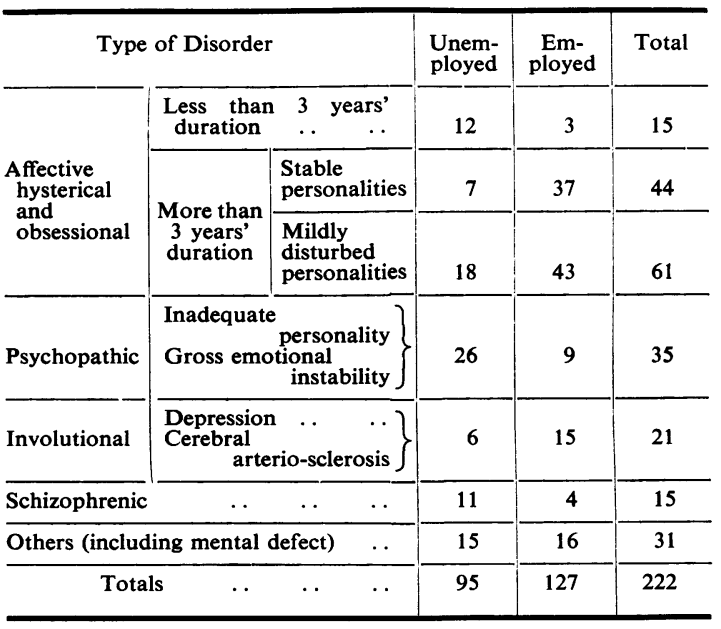

$\chi^{2}=47.8 ; P<0.001$ (6 d.f.)

Within the group of 105 subjects with more than 3 years' illness there is a clear association between severe mental ill-health and unemployment, which is statistically significant at the 0.1 per cent. level. There were eighty subjects in this group who were employed; of these subjects those who were improving in economic position were more often of stable personality and of better mental health, while those who were deteriorating in economic position were often of worse mental health with disturbed personalities. This last association was statistically significant at the 1 per cent. level.

(b) Involutional Illnesses.-In this group subjects with depression and those with organic deterioration may be classed together, for their problems of occupational adaptation are essentially the same. With the exception of one man aged 48 years, all the subjects were in the sixth and seventh decades, and showed the rigid personality pattern typical of such illnesses. Three-quarters of them were employed, and, although a number of them had been skilled workers, all were now employed in unexacting occupations: messenger, night-watchman, 
lift attendant, door-keeper, etc. Of the six who were unemployed, three were considered to be too ill to work: one had only recently been discharged from hospital and had probably not yet had time to find a suitable job, one was pensioned off and could not therefore be regarded as still part of the labour force, and information was lacking for the sixth.

(c) Schizophrenia.-Only four of these fifteen subjects were employed. Three of them had been discharged from hospital for over 5 years, and could be regarded as much improved. There were no signs of active schizophrenic illness in any of them, and they were all employed in unexacting occupations. The fourth, who had a mild chronic paraphrenic illness, had never been treated, and maintained a precarious and eccentric adjustment as labourer in a confectionery factory, where he held Bible meetings in the lunch-hour breaks. The personalities of all four were relatively wellpreserved. Of those who were unemployed, four were ill, exhibiting frank schizophrenic psychopathology, and in need of treatment, six had a chronic illness with deterioration and schizophrenic personality defects, although the illness was no longer active, and one had only recently been discharged from hospital.

(d) Inadequate Personality.-This diagnosis customarily leans heavily on the occupational history, but this is insufficient in a study which seeks to relate psychiatric illness and employment. The outstanding characteristic of these subjects was the inadequacy of their affective responses at the interview. The majority were unemployed, and the eight who were employed were in sheltered occupations, e.g. Remploy, Local Authority, hospitals. The impression was left that, although employed, these men were not in fact at work.

(e) Emotional Instability.-This was represented by a group of eight disturbed, difficult, and aggressive men. One man when interviewed roundly abused the authorities for not awarding him a pension, then admitted that he had not bothered to appeal against the tribunal's decision, and finally asked the investigator for a loan of $£ 50$. Another was under treatment for exhibitionism, and another had been sent to prison for forging his Post Office Savings Book. Only one man in this group was employed, and he was a clerk; it is to be noted that he was capable of more exacting work than the psychopaths of inadequate type in employment who were discussed in Section $(d)$.

(f) Mental Defect.-24 subjects were diagnosed as being feeble-minded, and the outstanding finding is the age distribution. With three exceptions, all the ten employed defectives were under 35 years of age, and all the fourteen unemployed defectives were aged 35 years or older. Data obtained from the Ministry of Labour do not confirm this finding, which must therefore be considered unreliable.

(g) Other Conditions.-The employed subject with G.P.I. was very similar in many ways to the group of employed subjects with involutional illnesses, and he was employed as a hospital porter. The unemployed subject was much deteriorated. The remaining five, who were all employed, were of stable personality, and some were employed in spite of a considerable physical handicap. The subject with thyrotoxicosis, for example, also suffered from angina pectoris and intermittent claudication; he had had to give up a job as sales representative owing to his difficulty in travelling, and now earns a livelihood by typing at home.

Table II summarizes the clinical findings which are relevant to employment, and there is a statistically significant association between these clinical groups and employment. In this Table the two groups of psychopathies have been added together, and the two groups of involutional illnesses; this is considered justifiable as the employment behaviour of the added groups is very similar. Mental defect was not considered separately because it was not thought to be a reliable figure.

Other Clinical Features.-Apart from diagnosis, the two groups of employed and unemployed subjects differed in other respects.* The following clinical features distinguished the unemployed: insomnia, loss of weight, hysterical conversion symptoms, ideas of reference, lack of irritability or aggressive outbursts, neglected appearance, disturbed mood, low or deteriorated intelligence (clinical estimate), presence of abnormal features in the mental state, lack of insight into the effect of their illness on their occupation, and greater attendance at out-patient clinics. They were more often suspicious or hostile at the interview, but only twelve of the unemployed and three of the employed showed any marked degree of resentment or hostility. In personality traits the unemployed tended to be immature, irresolute, lacking in social and personal responsibility, of shallow affect, and introverted. In the ischaemia pain endurance test the employed subjects complained sooner than did the unemployed. In all other clinical findings there was no significance difference between the two groups. In the Dominoes Test of general mental

* Unless otherwise stated, all the differences reported are statistically significant $(P<0 \cdot 05)$ 
ability the mean score of employed subjects was significantly higher than that of the unemployed. This difference was still upheld when the schizophrenic, feedle-minded, and organic disease of cases were excluded. Neither the mental health ratings nor the Cornell Index differentiated significantly between the two groups.

Personal and Social Data.-38 of the unemployed subjects were single men, 56 were married (including the twelve in which the marriage had been complicated by divorce or separation), and one was a widower. Of the employed 35 were single, 91 were married (including nine cases complicated by divorce or separation), and one was a widower. The higher proportion of single men amongst the unemployed is statistically significant when compared both with the employed and with the figures for London Administrative County (General Register Office, 1953).*

Further distinguishing features of the unemployed group were a disturbed or unhappy home atmosphere as a child, present marital unhappiness and domestic friction, deficient social interests and activities, and frequently a lack of service in the Forces. Few were receiving pensions.

There was a difference between employed and unemployed subjects in their attitude to their present

* It is of interest to note that the diagnoses of schizophrenia, psychopathy, and mental defect were made in nearly two-thirds of the unemployed single men. economic position: the majority of the employed subjects either definitely liked their work or were actively looking for a change of job, but the majority of the unemployed subjects were not very disturbed about their unemployment, although they were not satisfied.

Registration had been advised by the Ministry of Labour or the subject's doctor in many cases, but 31 of the employed subjects and five of the unemployed had registered as Disabled at the request of their employers. This difference is significant. Only eighteen of the unemployed subjects and 26 of the employed had attended Government Training Centres or Industrial Rehabilitation Units or had been employed by Remploy.

Occupations of Registered Psychiatrically DISABLED.-It was expected that the majority of disabled persons would be employed under certain special conditions. These conditions include no direct loss to the employer from inefficiency, no active pressure from competitors, and employments where national policies concerning disabled persons have most influence; these employments tend also to be those where the tasks are not exacting to the same degree as those in industrial employment for competitive markets.

These conditions obtain in all forms of employment by public utilities, and local and centralo government, and over half the employed subjects are found in such employments (Table III). The

TABLE III

COMPARISON OF PERCENTAGE DISTRIBUTIONS OF OCCUPATIONS OF REGISTERED PSYCHIATRICALLY DISABLED MEN

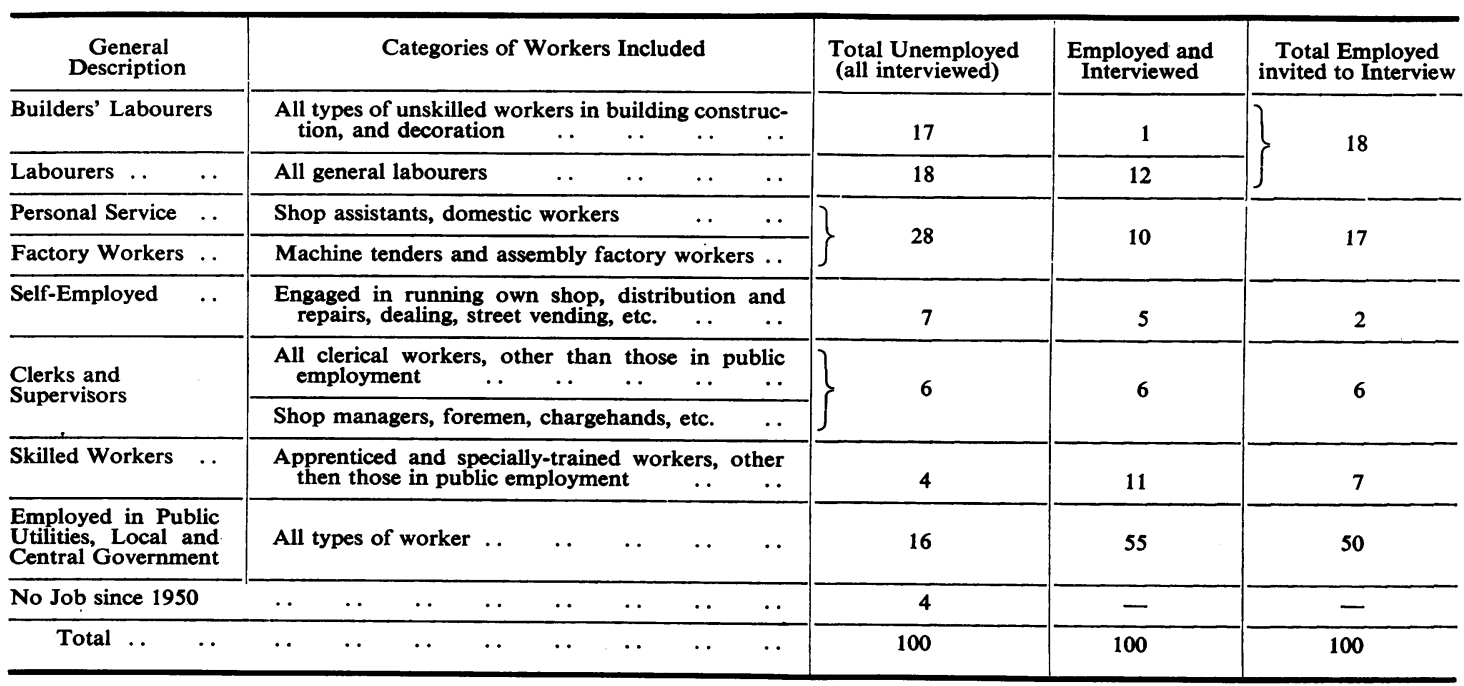


large difference between the proportion of employed and unemployed persons in these occupations also indicates that of disabled persons who are employed relatively few have fallen out of these employments. On the other hand, builders' labourers when disabled are particularly exposed to unemployment. The category of skilled workers shows exactly the opposite trend, for disabled persons when qualified and employed in their own crafts do not readily fall out of work.

Table III also shows that there is no material difference between employed subjects who volunteered to come for interview and those who did not. The difference between total employed and interviewed displayed in Categories 2 and 3 may be due to the precarious nature of employment, apprehension, and loss of earnings involved in coming for interview. That displayed in Categories 6 and 7 suggests that leave of absence could easily be obtained and may account for the slightly larger proportion among persons interviewed.

INCOME* AND FINANCIAL INCENTIVE TO RETURN To WORK.-The comparisons in Table IV were made to discover whether the group of unemployed men differed in earning capacity when last in employment from the group of employed men. - It will be seen that only the single men show a difference so large as to be clearly not due to changes in the value of money, or wage rates. This might support a contention that the unemployed single men are a differently constituted group from the employed single men (see Footnote on p. 42).

The financial incentive to return to work is indicated by the difference between the present income of the unemployed from all sources compared with the income obtained when last employed (Table IV). Most of the single men are however living with their parents, and, although regular payments were said to be made for board and lodging, in general such payments were excused if the parents or siblings were employed, and the financial incentive to return to work is correspondingly reduced for this group. Married men

* Includes family allowances, wife's earnings, etc. without dependants have therefore the highest incentive and in fact they form a smaller proportion of the unemployed than do single men or those with dependants (Table V).

TABLE V

PERCENTAGE DISTRIBUTION OF MARITAL STATUS OF UNEMPLOYED AND EMPLOYED REGISTERED PSYCHIATRICALLY DISABLED MEN

\begin{tabular}{|c|c|c|c|c|c|c|}
\hline \multicolumn{5}{|c|}{ Marital Status } & \multirow{2}{*}{\begin{tabular}{c|} 
Unemployed \\
34 \\
14 \\
52
\end{tabular}} & \multirow{2}{*}{$\begin{array}{c}\text { Employed } \\
38 \\
31 \\
31\end{array}$} \\
\hline $\begin{array}{l}\text { Married wi } \\
\text { Married wi } \\
\text { Single ... }\end{array}$ & out & $\begin{array}{l}\text { dants } \\
\text { pendant } \\
\ldots\end{array}$ & & $\begin{array}{l}\cdots \\
\cdots\end{array}$ & & \\
\hline Total & . & .. & .. & . & 100 & 100 \\
\hline
\end{tabular}

\section{(5) Discussion}

Adaptation is probably specific for each group of occupations. Table III indicates the range of occupations encountered in this study. These findings are further restricted in significance by the failure of many of the employed men to attend for interview. Their refusals cannot be attributed to their occupations, which were similar to those of the employed men who volunteered (Table III), but were probably due to differences in personality or mental health. Only tentative conclusions can be reached therefore in this discussion.

Clinical Findings.-Employed men tended to have rather higher wages and total income than those secured by the unemployed in their previous work. Failure to gain employment may therefore represent an acute episode in the chronic condition of lacking value in the labour market. Can such a condition be defined in psychiatric terms?

(a) Type of Illness. - The diagnosis does not seem to bear any special significance for occupational adaptation in these subjects, apart from the syndromes which imply particular types of personality structure or disorganization. In the previous investigation by Lewis (1935) a uniform clinical picture was observed in which hysteria was predominant, but this was not found in the present

TABLE IV

COMPARISON OF MODAL INCOMES (£), SHOWING FINANCIAL INCENTIVE TO RETURN TO WORK

\begin{tabular}{|c|c|c|c|c|c|}
\hline \multirow{2}{*}{\multicolumn{2}{|c|}{ Marital Status }} & \multirow{2}{*}{$\frac{\text { Employed }}{\text { Present Total Income }}$} & \multicolumn{2}{|c|}{ Unemployed } & \multirow{2}{*}{$\begin{array}{c}\text { Financial Incentive to } \\
\text { Return to Work } \\
\text { (2) - (3) }\end{array}$} \\
\hline & & & $\begin{array}{c}\text { Previous Total Income } \\
\text { (2) }\end{array}$ & $\begin{array}{c}\text { Present Total Income } \\
\text { (3) }\end{array}$ & \\
\hline $\begin{array}{l}\text { Married with Dependants } \\
\text { Married without Dependants } \\
\text { Single } \\
\text { S }\end{array}$ & $\begin{array}{l}\cdots \\
\cdots\end{array}$ & $\begin{array}{r}9 \cdot 2 \\
10 \cdot 0 \\
7 \cdot 0\end{array}$ & $\begin{array}{l}8 \cdot 3 \\
9 \cdot 0 \\
5 \cdot 4\end{array}$ & $\begin{array}{l}6 \cdot 0 \\
4 \cdot 8 \\
2 \cdot 0\end{array}$ & $\begin{array}{l}2 \cdot 3 \\
4 \cdot 2 \\
3 \cdot 4\end{array}$ \\
\hline
\end{tabular}


investigation. Moreover, gross hysterical features (tremor or pseudo-dementia) were found more frequently by Lewis than by the writers. The reasons for this difference are still far from clear, but it has been noted and discussed by other observers (Halliday, 1948).

(b) Mental Health.-There is evidence that a recent disturbance of mental health affects occupational adjustment adversely. It is uncertain however which is anterior in this relationship. It is likely, for example, that depression is a direct consequence of being without work; some of the unemployed have been seen again since the survey was made, and there has been an obvious lightening of mood in those who have found work. Further follow-up studies are needed to elucidate this problem, but it is already clear that unemployment and mental ill-health have an effect of mutual enhancement.

The ratings of mental health and the Cornell questionnaire provided no evidence to suppose that the unemployed men were, as a group, more severely ill than the employed. Although, therefore, mental health is one factor in occupational adjustment, it is plainly insufficient to account for all the findings.

(c) Personality.-The findings in this investigation leave small doubt that the occupational adaptation of these subjects is largely governed by quality of personality. The analysis of the ratings of personality traits indicates the qualities which engender poor adaptation, and this clearly reflects the finding that unemployment is heaviest in the groups of inadequate and unstable personalities, and in schizophrenia. Even in the neurotics who were employed, the economic position of those with disturbed personalities tended to deteriorate. Another aspect of the differences in personality between the employed and unemployed groups of subjects is to be seen in their attitude to their present economic position and in their poor use of leisure; it may be that these men are ineffectual in all their activities.

Such findings were adumbrated in previous investigations, although in this respect there is an interesting discrepancy: bitter and resentful attitudes were not often found during the present study. This is not easy to explain: for the unemployed the world is patently a different place now from what it was when Lewis first made his observations in 1931, yet the "welfare state" had failed to assuage the bitterness of the control group of disabled men reported by Jones (1952), or of the disabled men examined by Hewitt (1949).
It is easier to talk about "personality traits" than to define them. At best they are illuminating inferences from observed behaviour, and they may be much less than that. Moreover, the separation of "personality" from "mental health" is at times arbitrary, as in the diagnosis of psychopathic personality, so that a more accurate statement would be that in the subjects investigated the permanent characteristics of a person's behaviourrevealed both in the history and on psychiatric examination-are of the first importance in determining the subject's occupational adjustment.

Socio-Economic Findings.-The most important fact arising from the socio-economic findings is the difference in the levels of financial incentive offered to the three groups of men (married with dependants, married without dependants, and single). As the earning potential of the unemployed person decreases, so the financial incentive to resume work also tends to decrease in effectiveness, even to the extent that among those having the lowest earnings when employed the adjustment of choice might be a state of unemployment. The work records of the unemployed often show a surprising degree of familiarity with the regulations and conditions governing the payment of benefits of all types, and betray a skill in manipulating these regulations which in itself represents a high degree of "adaptation".

RehabiLITATION.-Two separate problems seem to be involved. Men with stable or well-preserved personalities, especially those who have only recently fallen ill, merit the maximum attention from those responsible for resettlement. Such men are likely to return to industry as efficient workers regardless of diagnosis, and it is possible that the period of total disablement could be reduced. The re-employment of men with inadequate personalities, however, may not amount to much more than a social service; the impression formed by the present investigators was that such men are not able to compete successfully with more productive workers. Careful assessment of personality is needed to obtain successful resettlement, and this requires closer co-operation between the doctor and the disablement resettlement officer than can be obtained from the simple filling in of a form.

\section{SUMMARY}

(1) 222 men, all registered as disabled persons through psychiatric conditions, were examined; 95 were unemployed and 127 employed. 
(2) The clinical and social histories of the employed and unemployed men were contrasted and compared.

(3) The following tentative conclusions were reached:

(a) Occupational adaptation is primarily determined by the personality of the subject.

(b) The subject's occupational adaptation is adversely affected by recent disturbances of the mental state, but not so much as by disturbances of the personality.

(c) The type of mental disorder is without significance for occupational adaptation unless it also implies a serious personality disturbance.

(d) Subjects who can earn only low wages have little or no financial incentive to regain employment.

(4) Successful rehabilitation of the psychiatrically disabled largely turns on whether the worker previously had a stable personality and a satisfactory work record.

Acknowledgments are made to Professor Aubrey Lewis, Honorary Director of the Unit, for guidance and criticism throughout, and to Dr. G. M. Carstairs for special assistance in the "follow-up" clinic. The preparations for, and the planning of, the survey were greatly assisted by conferences with the headquarters staff of the Ministry of National Insurance, the London and SouthEastern Regional Office of the Ministry of Labour and National Service, and the National Assistance Board. This investigation could not have been carried out without the invaluable co-operation and suggestions of the Group Disablement. Resettlement Officer, and the Managers and Disablement Resettlement Officers of the South London Area.

\section{REFERENCES}

Eisenberg, P., and Lazarsfeld, P. F. (1938). Psychol. Bull., 35, 358. General Register Office (1953). "Census 1951, County Report." H.M.S.O., London.

Guttman, E., and Thomas, E. L. (1946). "A Report on the Re-adjustment in Civil Life of Soldiers discharged from the Army on account of Neurosis." Ministry of Health Reports on Public Health and Medical Subjects, No. 93. H.M.S.O., London.

Halliday, J. L. (1948). "Psychosocial Medicine", p. 112. Heinemann, London.

Harris, A., and Lane, M. A. (1949). Brit. med. J., 1, 982.

Hewitt, M. (1949). Lancet, 2, 523.

Israeli, N. (1935). J. appl. Psychol., 19, 67.

Jones, M. (1952). "Social Psychiatry." Tavistock Publications, London.

Lewis, A. (1935). Lancet, 2, 293.

Markowe, M., and Barber, L. E. D. (1952). Brit. J. industr. Med., 9, 221 .

9, (1953a). Ibid., 10, 125.

7,205 .

Morton, N. W. (1935). “Occupational Abilities: a Study of Unemployed Men", p. 96. Oxford Univ. Press, Toronto.

Stalker, H. (1945). Brit. J. phys. Med., 8, 18. 